\title{
Fish communities diverge in species but converge in traits over three decades of warming
}

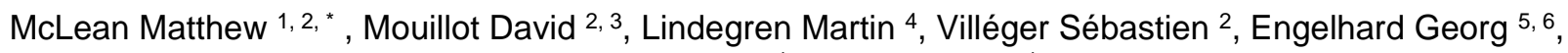 \\ Murgier Juliette ${ }^{1}$, Auber Arnaud ${ }^{1}$
}

1 Unité Halieutique de Manche et mer du Nord IFREMER Boulogne-sur-Mer, France

2 MARBEC, Université de Montpellier, CNRS, IFREMER, IRD Montpellier Cedex, France

${ }^{3}$ Australian Research Council Centre of Excellence for Coral Reef Studies James Cook University

Townsville Qld ,Australia

${ }^{4}$ Centre for Ocean Life National Institute of Aquatic Resources, Technical University of Denmark

Lyngby ,Denmark

${ }^{5}$ Centre for Environment, Fisheries \& Aquaculture Science (Cefas) Lowestoft ,UK

${ }^{6}$ Collaborative Centre for Sustainable Use of the Seas (CCSUS) University of East Anglia Norwich ,UK

* Corresponding author : Matthew McLean, email address : mcleamj@gmail.com

\begin{abstract}
:
Describing the spatial and temporal dynamics of communities is essential for understanding the impacts of global environmental change on biodiversity and ecosystem functioning. Trait-based approaches can provide better insight than species-based (i.e. taxonomic) approaches into community assembly and ecosystem functioning, but comparing species and trait dynamics may reveal important patterns for understanding community responses to environmental change. Here, we used a 33-year database of fish monitoring to compare the spatio-temporal dynamics of taxonomic and trait structure in North Sea fish communities. We found that the majority of variation in both taxonomic and trait structure was explained by a pronounced spatial gradient, with distinct communities in the southern and northern North Sea related to depth, sea surface temperature, salinity and bed shear stress. Both taxonomic and trait structure changed significantly over time; however taxonomically, communities in the south and north diverged towards different species, becoming more dissimilar over time, yet they converged towards the same traits regardless of species differences. In particular, communities shifted towards smaller, faster growing species with higher thermal preferences and pelagic water column position. Although taxonomic structure changed over time, its spatial distribution remained relatively stable, whereas in trait structure, the southern zone of the North Sea shifted northward and expanded, leading to homogenization. Our findings suggest that global environmental change, notably climate warming, will lead to convergence towards traits more adapted for novel environments regardless of species composition.
\end{abstract}

Keywords : biotic homogenization, climate change, community ecology, ecological traits, ecosystem functioning, fisheries, functional diversity, spatio-temporal dynamics 


\section{Introduction}

Evaluating the spatial and temporal dynamics of fish communities is crucial for understanding and predicting the impacts of global environmental change on marine ecosystem functioning and services (Frainer et al., 2017; Givan, Edelist, Sonin, \& Belmaker, 2018; Holmlund \& Hammer, 1999; Worm et al., 2006). Fishes are the dominant vertebrates in marine food webs and strongly influence ecosystem processes such as nutrient cycling, carbon storage, water quality, and habitat maintenance (Allgeier, Burkepile, \& Layman, 2017; Bascompte, Melián, \& Sala, 2005; Holmlund \& Hammer, 1999; Villéger, Brosse, Mouchet, Mouillot, \& Vanni, 2017). In recent decades, ocean warming has profoundly impacted marine fish communities (Cheung, Watson, \& Pauly, 2013; Flanagan, Jensen, Morley, \& Pinsky, 2019; Fossheim et al., 2015; Wernberg et al., 2016). Examining spatial and temporal changes in fish communities under warming can provide insight into ecological responses to climate change, and how ecosystem structure may change in the future (Auber, Travers-Trolet, Villanueva, \& Ernande, 2015; Beukhof, Dencker, Pecuchet, \& Lindegren, 2019; Dencker et al., 2017). Additionally, observational studies can provide robust results for understanding community dynamics and improving predictive models (Mouillot, Graham, Villéger, Mason, \& Bellwood, 2013; Suding et al., 2008). Thus, examining fish community dynamics over the last 20-30 years may be particularly useful for understanding how climate change will affect marine ecosystem structure and functioning.

While marine ecologists have traditionally used species-based (i.e., taxonomic) approaches to assess fish community dynamics, trait-based approaches may better reveal mechanisms structuring communities (Tillin, Hiddink, Jennings, \& Kaiser, 2006; Bremner, Rogers, \& Frid, 2003; McLean, Mouillot, \& Auber, 2018). In place of species or taxa, such approaches use bio-ecological traits that characterize organisms' responses to environmental change or effects on ecosystem processes (Díaz \& Cabido, 2001; Mouillot, Graham, Villéger, 
Mason, \& Bellwood, 2013). Over the last few decades, and especially in recent years, traitbased approaches have been shown superior to taxonomic approaches for examining community assembly and ecosystem functioning (Lavorel \& Garnier, 2002; Mouillot, Graham, Villéger, Mason, \& Bellwood, 2013; Pecuchet et al., 2017; Sakschewski et al., 2016; Weiher \& Keddy, 1995). Yet, examining changes in taxonomic and trait diversity simultaneously may best describe community dynamics (Dencker et al., 2017; Monnet et al., 2014; Villéger et al., 2010). For instance, changes in species composition may not lead to changes in trait diversity if loser species are replaced by species with similar traits (Clare, Robinson, \& Frid, 2015; Villéger et al., 2010; White, Montgomery, Storchová, Hořák, \& Lennon, 2018). Conversely, declines of a few rare species with unique trait values may have major impacts on trait diversity without notable changes in species composition (Mouillot et al., 2014; Mouillot et al., 2013; Violle et al., 2017).

A variety of studies have documented biotic homogenization in marine and terrestrial communities in response to anthropogenic pressure and climate change (Devictor et al., 2008; Magurran, Dornelas, Moyes, Gotelli, \& McGill, 2015; Richardson, Graham, Pratchett, Eurich, \& Hoey, 2018). In particular, homogenization of species' traits (i.e., 'functional homogenization') is leading to losses in biodiversity and likely ecosystem functioning given links between organismal traits and ecosystem process (Devictor et al., 2008; Olden, LeRoy Poff, Douglas, Douglas, \& Fausch, 2004). For example, in many ecosystems specialist species with unique functional roles are being replaced by generalists more adapted to disturbed environments (Clavel, Julliard, \& Devictor, 2011), and such losses could deteriorate ecosystem services (Clavel et al., 2011; Devictor et al., 2008; Mouillot et al., 2013). However, most studies have examined biotic homogenization through species-based approaches, which offer less insight for understanding the mechanisms driving homogenization and the consequences for ecosystem function. Yet, trait homogenization 
often results from taxonomic homogenization, and the relationship between trait homogenization and taxonomic homogenization is not entirely understood (Baiser \& Lockwood, 2011; White et al., 2018).

Here, using fish monitoring data spanning 33 years, we assessed and compared spatiotemporal patterns of fish taxonomic and trait structure in the North Sea, specifically examining how fish communities were spatially structured throughout the North Sea and how these spatial patterns in taxonomic and trait structure have changed over time.

\section{Materials and Methods}

\section{Study area}

The North Sea is a continental shelf sea of northwestern Europe that is connected to the North Atlantic Ocean through the Norwegian Sea in the north and the English Channel in the South. The North Sea is a large and relatively shallow marine ecosystem with a surface area of $570,000 \mathrm{~km}^{2}$ and depths generally between $30-50 \mathrm{~m}$ in the south and 50-100 $\mathrm{m}$ in the north (Kenny, Skjoldal, Engelhard, Kershaw, \& Reid, 2009). The ecosystem has a long history of overfishing, particularly during the late $20^{\text {th }}$ century, with notable declines in species such as cod, haddock, and whiting (Aadland, 1993; Frid, Harwood, Hall, \& Hall, 2000; Gislason, 1994). The North Sea is considered a global warming hotspot, with temperatures rising at nearly four times the global average (Hobday \& Pecl, 2014), and has experienced considerable climate impacts over the past thirty years, including major changes in fish communities (Montero-Serra, Edwards, \& Genner, 2014; Simpson et al., 2011). Recent studies have also documented notable changes in trait diversity (Dencker et al., 2017; Somerfield, Clarke, Warwick, \& Dulvy, 2008), particularly in the southern North Sea (McLean et al., 2018). However, long-term changes in spatial structure have not been fully 
examined and whether taxonomic and trait dynamics have followed similar trajectories remains unknown.

\section{Fish community data}

Fish community data came from the International Bottom Trawl Survey (IBTS), an annual monitoring campaign that uses stratified random sampling to survey fish communities in approximately $150,1^{\circ}$ longitude $\times 0.5^{\circ}$ latitude survey cells covering the entire North Sea each year in early February. During each survey, a 3-m vertical opening bottom trawl (i.e., GOV trawl) with a $10-\mathrm{mm}$ mesh codend is towed for $30 \mathrm{~min}$ at an average speed of 4 knots. In each survey, fishes are identified and counted, and the resulting abundances are standardized to numbers of individuals per $\mathrm{km}^{2}$. IBTS abundance data were obtained from the International Council for Exploitation of the Sea (ICES). These data were extracted for the period 1983 to 2015 for ICES areas IVa, IVb and IVc, which together encompass the entirety of the North Sea. The final fish abundance dataset included 130 taxa (115 species, 15 identified to genera only) across 154 survey cells over 33 years, for a table containing 130 columns and 4924 rows (some years did not include all 154 survey cells). Prior to all statistical analyses, the entire table of species' abundances (across all survey cells and years) was $\log _{10}(\mathrm{x}+1)$ transformed.

\section{Ecological traits}

Selecting traits requires careful consideration because universal agreements do not exist on trait number or importance, and trait choice ultimately determines research conclusions (Lefcheck, Bastazini, \& Griffin, 2015; Lepš, de Bello, Lavorel, \& Berman, 2006; Zhu et al., 2017). Dee et al. (2016) and Mcgill et al. (2006) stated that trait choice should be based on explicit hypotheses and Botta-Dukát (2005) and Petchey \& Gaston (2006) stated that traits 
should reflect well-defined ecological roles or functions. Studies have shown that the ability to predict community dynamics increases sharply with an increasing number of traits (Frenette-Dussault, Shipley, Meziane, \& Hingrat, 2013; Shipley, Laughlin, Sonnier, \& Otfinowski, 2011); however, Laughlin (2014) showed that predictive power saturates at around eight traits. Here, nine traits related to life history, habitat use, and trophic ecology were collected for each taxa. These included length and age at maturity, fecundity, parental care, offspring size, water column position, thermal preference, trophic level, and trophic guild (Table S1). Trait data came primarily from FishBase (Froese \& Pauly, 2012), Engelhard, Ellis, Payne, ter Hofstede, \& Pinnegar (2011), and Pecuchet et al. (2017). Traits encompassing life history, habitat use, and trophic ecology were chosen because they are believed to mediate species' responses to environmental change (Beukhof, Dencker, Pecuchet, \& Lindegren, 2019; McLean et al., 2018; Villéger et al., 2017). For instance, length and age at maturity can mediate species' environmental responses because they determine growth rate, metabolism, and generation time (Brown, Gillooly, Allen, Savage, \& West, 2004; Petchey, Beckerman, Riede, \& Warren, 2008), Similarly, fecundity, offspring size, and parental care determine population growth, dispersal capacity, and survivorship (Adams, 1980; Gross \& Sargent, 2015; Keck et al., 2014; Lambert, 2008; Ware, 1975; Winemiller \& Rose, 1992). Trophic level and trophic guild determine species' responses to resource fluctuations and mediate predator-prey interactions and trophic cascades (Duffy et al., 2007; Gravel, Massol, \& Leibold, 2016; Huxel \& McCann, 1998; Schneider, Brose, Rall, \& Guill, 2016; Winemiller \& Rose, 1992). Water column position influences species' distributions, mobility, and habitat requirements (Montero-Serra, Edwards, \& Genner, 2014; Rijnsdorp, Peck, Engelhard, Möllmann, \& Pinnegar, 2009; Winemiller, Fitzgerald, Bower, \& Pianka, 2015), and thermal preference dictates species' tolerances to temperature changes (Dee et al., 2016; Givan, Edelist, Sonin, \& Belmaker, 2017). This set of traits was chosen to adequately 
characterize species' ecological profiles without including redundant or overly-correlated traits, and the maximum correlation among numeric traits was 0.59 (mean $=0.37$ ), well below proposed collinearity thresholds (Dormann et al., 2013). Additionally, missing trait data was not an issue as the final dataset contained $98 \%$ of all possible trait values. Lastly, here we used single, fixed trait values for each species, which cannot account for spatial or temporal variation in species' traits (e.g., fishing-induced size reduction) or trait plasticity; however, the goal of this study was not to examine individual population demographics but rather to examine how interspecific differences in species' traits explain community responses to environmental pressures.

To characterize trait-based community structure, we then calculated communityweighted mean trait values (CWMs) for the entire dataset across all survey cells (143 - 154 per year) and years (33 years). CWMs are calculated as the abundance-weighted mean trait values in the community, which result in single, numeric values for continuous traits, and proportions for categorical traits. Because CWMs as averages, they reflect relative changes in trait structure in the community rather than absolute increases or decreases.

\section{Spatial vs temporal variation}

To assess the relative importance of space vs. time in explaining the overall variation in both taxonomic and trait-based community structure, we first applied redundancy analysis (RDA), a multivariate method for examining the variation in a set of response variables (e.g., fish communities) using a set of explanatory variables (Borcard, Gillet, \& Legendre, 2011). For taxonomic structure, we performed two separate RDAs with i) survey cells, and ii) years as explanatory factors, and species' abundances as dependent variables. For trait structure, we applied the same RDAs but with CWM trait values as dependent variables.

This article is protected by copyright. All rights reserved. 


\section{Spatial clustering}

We then examined whether there were identifiable spatial clusters of taxonomic and trait structure using K-means clustering, a least-squares partitioning method for finding data groupings (Borcard et al., 2011). For both taxonomic and trait structure, we calculated the mean community composition (species' abundances or CWMs) for each survey cell for the overall time series in order to apply K-means clustering across survey cells and identify distinct spatial zones. For taxonomic structure, we used the Bray-Curtis distance, while for trait structure we used the Euclidean distance. The optimal number of clusters was chosen using the R package NbClust, which integrates multiple indices of cluster optimization.

\section{Ordinations}

Next, to examine overall spatio-temporal taxonomic and trait structure and to identify the species and traits most associated with spatial and temporal community variation, we built ordinations of the entire taxonomic and trait structure datasets. For taxonomic community structure we used Principal Coordinates Analysis (PCoA), an ordination method that transforms community data into a multidimensional space that best represents the overall variation of the data (Borcard et al., 2011). PCoA was applied to a Bray-Curtis dissimilarity matrix of species abundance data. This procedure created an ordination of all 4942 communities in the dataset (all survey cells across all years) with the relative positions and distances of communities representing their taxonomic similarity. For trait structure, we first standardized the CWM trait values (by subtracting each value from the mean and dividing by the standard deviation, function scale in R) and then applied Multiple Factor Analysis (MFA), an ordination method that can give equal weighting to all traits. Because categorical traits have several groups (e.g., pelagic, benthopelagic, demersal) they can be over-weighted by traditional ordination techniques that treat each trait group as an individual entity. As with 
PCoA, MFA created an ordination representing the trait similarity of all 4942 communities in the dataset.

\section{Environmental drivers of overall spatio-temporal variation}

In order to contextualize fish community dynamics, we next identified the environmental variables with the greatest associations with overall spatio-temporal variation in both taxonomic and trait structure. This was accomplished using RDA with environmental variables as explanatory factors and species' abundances or CWM trait values as dependent variables. For taxonomic structure, we specifically used distance-based redundancy analysis (dbRDA) with the Bray-Curtis distance in order to avoid the problem of double zero similarity in species' abundances (Borcard et al., 2011), while for trait structure we used RDA with the Euclidean distance. Environmental variables included depth, sea surface temperature (SST), salinity, and bed shear stress (i.e., water velocity over the bottom). Depth was recorded in-situ during fish community surveys. Mean-annual SST data for each survey cell were derived from the Hadley Centre for Climate Prediction and Research's freely available HadISST1 database (Rayner et al., 2003). Salinity data came from the NORWegian ECOlogical Model NORWECOM (Skogen, Svendsen, Berntsen, Aksnes, \& Ulvestad, 1995). Bed shear stress data came from a 3D hydrodynamic model developed by Aldridge \& Davies (1993).

Because a variety of data were unavailable prior to the late 1990s, we also ran additional dbRDA and RDA analyses to identify the primary drivers of spatial community structure. For these analyses we included not only depth, SST, salinity, and bed shear stress, but also chlorophyll- $a$, suspended sediment, and fishing effort. Chlorophyll-a and suspended sediment were derived from satellite data and were available from 1998 - 2015 (Gohin, 2011). Fishing effort (number of hours fished) by beam trawls and otter trawls came from 
Jennings et al. (1999) and was available for the period 1990 - 1995. Because our data incorporated both demersal and pelagic species, we combined beam and otter trawls together into total fishing effort. In order to conduct spatial analyses, for each variable, we calculated the average value per survey cell for the overall time series available. Thus for depth, SST, salinity, and bed shear stress, the value for each cell was the mean from $1983-2015$, for chlorophyll- $a$ and suspended sediment the value was the mean from $1998-2015$, and for fishing effort the value was the mean from 1990 - 1995. Spatial RDAs were conducted for both taxonomic and trait structure, and forward variable selection (R function ordistep) was used to identify the most parsimonious models, and variable importance was assessed according to adjusted $\mathrm{R}^{2}$ values.

\section{Temporal dynamics of spatial clusters}

In order to examine the temporal dynamics of spatial clusters (see section 'Spatial clustering' above), for each year we first calculated the centroid (i.e., mean position) of all survey cells for each cluster in the ordination spaces (PCoA for taxonomic, MFA for traits). We then examined the temporal trajectories of each cluster in the ordination spaces and tested whether clusters' community structures had significantly changed through time using linear regressions of each cluster's first and second axis positions (PCoA and MFA scores) against time. To visualize overall spatio-temporal changes in taxonomic and trait structure, we then generated annual krigging-interpolated maps of PCoA1 and MFA1 scores across the entire North Sea. Next, to assess whether spatial clusters have become more or less similar through time, for each year we calculated the Euclidean distance between cluster centroids in the ordination spaces (across all n-dimensions) and tested whether or not distances between clusters have increased or decreased using linear regressions. To further assess temporal changes in spatial heterogeneity, we also examined annual i) Bray-Curtis taxonomic beta 
diversity and ii) trait-based beta diversity for the entire North Sea, and tested for changes using linear regressions. Bray-Curtis taxonomic beta diversity was calculated using the $\mathrm{R}$ function beta.multi.abund (Baselga, 2017). Trait-based beta diversity was calculated following Chao et al. (2019) using the R function MultiFD.Beta, where beta diversity is a modified version of Rao's quadratic entropy that gives equal importance to species' trait differences and species' abundances.

In order to identify the species and traits most strongly associated with temporal changes in taxonomic and trait structure in each cluster, we next ran individual cluster-level analyses. For each cluster, we applied partial redundancy analyses (pRDA), a form of RDA (or dbRDA for taxonomic) that controls for and removes the influence of a confounding variable. We applied pRDA to remove the influence of spatial variation within each cluster and examine only temporal variation, and we extracted species and trait scores along the first axis (the axis associated with time) to assess their contributions to overall temporal changes. In the pRDA for trait structure, columns in the CWM trait table were weighted using trait weights from the initial MFA analysis so that the individual groups within categorical traits were not treated as individual traits themselves, but rather groups within a single trait (e.g., piscivore and planktivore within the trait trophic guild).

Lastly, to evaluate whether the location or extent of spatial clusters have shifted through time, we applied K-means clustering to the entire taxonomic and trait datasets (species abundance and CWM tables with 4942 rows) and then subsetted the data for each year and examined changes in the mean latitude and surface area of each cluster through time.

This article is protected by copyright. All rights reserved. 


\section{Results}

\section{Spatio-temporal variation in taxonomic and trait structure}

Initial RDAs revealed that overall variation in both taxonomic and trait structure was overwhelmingly explained by space, indicating major differences in community structure across sites that may have been maintained through time. Specifically, for taxonomic structure, space explained 24 times more variation than time $(56.1 \%$ vs. $2.3 \%)$, while for trait structure space explained 16 times more variation than time (41\% vs. $2.5 \%)$. K-means clustering then identified two distinct spatial clusters in both taxonomic and trait structure corresponding to the northern and southern areas of the North Sea (Figure 1). This further indicated that the vast majority of spatio-temporal variation in both taxonomic and trait structure in North Sea fish communities corresponded to pronounced spatial patterns.

The first PCoA axis of taxonomic structure captured $38.8 \%$ of the overall spatiotemporal variation, while the first MFA axis of trait structure captured $36.7 \%$ of overall variation (Figure 1). The environmental RDAs revealed that these patterns corresponded to a north-south spatial gradient of depth, sea surface temperature, salinity, and bed shear stress, which were all identified as significant explanatory factors (taxonomic dbRDA: $F_{4,3417}=360$, $p<0.001$; trait-based RDA: $F_{4,3417}=362.1, p<0.001$; Figure 2). Taxonomic structure was characterized by higher abundances of Norway pout (Trisopterus esmarkii), haddock (Melanogrammus aeglefinus), long rough dab (Hippoglossoides platessoides), argentine (Argentina spp.), grey gurnard (Eutrigla gurnardus), saithe (Pollachius virens), and mackerel (Scomber scombrus) in the northern North Sea, which is deeper, colder (on average throughout the year), and has higher salinity and lower bed stress, while sprat (Sprattus sprattus), plaice (Pleuronectes platessa), dab (Limanda limanda), herring (Clupea harengus), solenette (Buglossidium luteum), and flounder (Platichthys flesus) were more abundant in the southern North Sea, which is shallower and warmer (on average) with lower salinity from 
river discharge and higher bed stress from tidal currents (Top 10\% of weighted average species scores, $n=130$ total; Figures $1-2$ ). Overall variation in trait structure was characterized by higher mean length at maturity, trophic level, age at maturity, and fecundity as well as greater relative abundances of piscivores in the northern North Sea, while pelagics and planktivores were relatively more abundant in the southern North Sea (Top 30\% of trait loadings, n=23 total; Figures 1-2).

\section{Spatial drivers of fish community structure}

The most parsimonious model of spatial taxonomic structure retained all variables, and variable inflation factors did not exceed six (VIF threshold 10; see Borcard et al., 2011) (dbRDA: $F_{7,123}=31.7, p<0.001$; Figure S1a). Depth was by far the most important variable in explaining spatial community structure $\left(R_{a d j}^{2}=0.47\right)$, followed by $\operatorname{SST}\left(R_{a d j}^{2}=0.40\right)$, chlorophyll- $a\left(R_{a d j}^{2}=0.39\right)$, salinity $\left(R_{a d j}^{2}=0.25\right)$, bed shear stress $\left(R_{a d j}^{2}=0.19\right)$, suspended sediment $\left(R_{a d j}^{2}=0.11\right)$, and lastly fishing effort $\left(R_{a d j}^{2}=0.07\right)$. Chlorophyll- $a$ and suspended sediment were substantially higher in the southern North Sea, while fishing pressure was also highest in the southern North Sea and along the western coast (i.e., United Kingdom), with relatively little fishing effort in the deep, northern North Sea (see Jennings et al., 1999). Similarly, the most parsimonious model of trait structure included all variables except suspended sediment (RDA: $F_{6,124}=21.4, p<0.001$; Figure S1b). Again depth had the highest

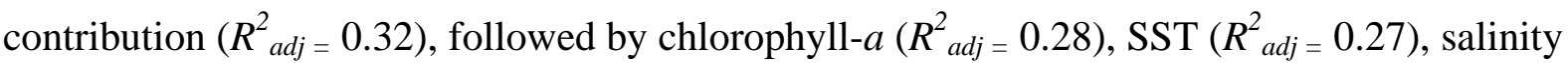

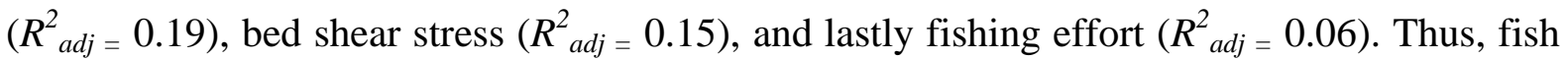
communities in the northern North Sea were associated with not only deeper, colder waters but also lower primary productivity and lower fishing effort, while communities in the southern North Sea were associated with shallower, warmer waters with higher primary productivity and greater fishing effort. Lastly, to examine the potential influence of 
aggregating total fishing effort, we additionally re-ran spatial analyses with beam trawls and otter trawls separately, and both analyses provided the same results as total fishing effort.

\section{Temporal changes in taxonomic and trait structure}

Taxonomically, we found that both the southern and northern North Sea changed significantly in species composition over time, as the southern cluster shifted along both PCoA1 and PCoA2 (PCoA1: $F_{1,31}=73.3, p<0.001$; PCA2: $F_{1,31}=32.4, p<0.001$ ), and the northern cluster shifted along PCoA2 $\left(F_{1,31}=290.4, p=<0.001\right.$; Figure 3$)$. These changes were also evident for ecological traits, as both the southern and northern cluster shifted significantly in trait composition along both MFA1 and MFA2 over time (southern MFA1: $F_{1,31}=97.8, p<0.001$, southern MFA2: $F_{1,31}=18.3, p<0.001$; northern MFA1: $F_{1,31}=$ 281.1, $p<0.001$, northern MFA2: $F_{1,31}=50.4, p<0.001$; Figure 3). However, the taxonomic clusters appeared to move further apart along PCoA1, indicating divergence in community structure between the southern and northern areas, whereas trait-based clusters seemed to converge, potentially becoming more similar through time (Figure 3). Kriging-interpolated maps of PCoA and MFA scores then clearly highlighted the taxonomic divergence and trait convergence of fish communities, as the southern and northern North Sea became progressively more dissimilar taxonomically, but both areas shifted toward similar trait values (MFA scores) (Figure 4). Examining temporal trends in Euclidean distances between cluster centroids in ordination spaces then confirmed that taxonomic clusters became significantly more dissimilar through time $\left(F_{1,31}=19.3, p<0.001\right)$, while trait-based clusters became significantly more similar $\left(F_{1,31}=4.8, p<0.05\right.$; Figure 5). Additionally, by examining temporal trends in taxonomic and trait-based beta diversity for the entire North Sea, we found that the overall ecosystem has become more dissimilar in taxonomic structure,

This article is protected by copyright. All rights reserved. 
but more similar in trait structure (Bray-Curtis beta: $F_{1,31}=56.14, p<0.001$; trait-based beta: $F_{1,31}=6.5, p<0.05 ;$ Figure 5).

Interestingly, examining cluster movements alongside environmental variables further indicated that despite taxonomic divergence, both trait-based clusters shifted towards communities more associated with higher SSTs (Figures 1-3). Species scores from individual cluster analyses (partial dbRDAs) then showed that the southern North Sea became progressively more characterized by solenette (Buglossidium luteum), sprat (Sprattus sprattus), grey gurnard (Eutrigla gurnardus), scaldfish (Arnoglossus spp.), and anchovy (Engraulis encrasicolus), and less characterized by poor cod (Trisopterus minutus) and cod (Gadus morhua), while the northern North Sea became more characterized by grey gurnard (Eutrigla gurnardus), horse mackerel (Trachurus trachurus), hake (Merluccius merluccius), argentine (Argentina spp.), poor cod (Trisopterus minutus), and dragonet (Callionymus spp.), and less characterized by haddock (Melanogrammus aeglefinus) (Top 5\% of species scores; Figure S2). However, both clusters shifted primarily toward the same traits, becoming progressively more characterized by higher thermal preferences, pelagic water-column position, lower length at maturity, lower trophic level, and lower fecundity. Additionally, the southern North Sea became relatively less characterized by piscivores and species with pelagic eggs, while the northern North Sea became more characterized by lower age at maturity and less characterized by benthopelagic water-column position (Top 30\% of trait loadings; Figure S3).

\section{Changes in the extent and location of spatial clusters}

Although both taxonomic clusters exhibited changes in community structure over time, only the northern cluster changed significantly in mean latitude, moving, on average, slightly northward $\left(F_{1,31}=46, p<0.001\right)$. However, the southern cluster expanded significantly in 
surface area over time $\left(F_{1,31}=35.6, p<0.001\right)$, while the northern cluster retracted slightly $\left(F_{1,31}=6.6, p<0.05\right.$; Figure S4). For trait structure, both the southern and northern cluster shifted significantly northward over time (southern: $F_{1,31}=35.4, p<0.001$; northern: $F_{1,31}=$ $82.5, p<0.001)$, leading to a marked expansion of the southern cluster $\left(F_{1,31}=103.7, p<\right.$ $0.001)$, and a reduction of the northern cluster $\left(F_{1,31}=72.3, p<0.001\right.$; Figure S5). While both taxonomic and trait-based clusters shifted in spatial location and extent over time, the traitbased changes were much greater, as the surface area of the northern cluster was originally two times larger than the southern cluster, but became slightly smaller than the southern cluster by the end of the time series (Figure 4, Figure S5).

\section{Discussion}

Here, using long-term, spatially-resolved survey data, we documented strikingly similar spatial patterns in taxonomic and trait structure in North Sea fish communities, with distinct southern and northern clusters; however, the temporal dynamics of these clusters differed substantially. We found that the southern and northern North Sea converged toward similar trait structures despite diverging in species composition through time. Additionally, as the southern and northern areas became homogenized in ecological traits, the southern area expanded northward, significantly altering spatial structure. These results have important implications, demonstrating that communities may respond to environmental change by converging toward trait structures better-suited to novel environments. Hence, fish communities under similar environmental pressures appear capable of converging toward similar trait structures even through changes in entirely different species. While such results have been observed in experimental plant communities (Fukami, Martijn, Mortimer, \& Putten, 2005), ours is a novel example showing temporal trait convergence in marine fish communities driven by taxonomically different species. 
As a global warming hotspot (Hobday \& Pecl, 2014), the North Sea has been heavily impacted by temperature rise over the last few decades, with documented increases in fishes with small body sizes and fast life history strategies, particularly pelagic species (Beukhof, Dencker, Pecuchet, \& Lindegren, 2019; McLean et al., 2018; Pecuchet et al., 2017; Simpson et al., 2011). Previous studies have suggested that such species can rapidly track environmental changes due to short generation times, fast population turnover, and by producing small, pelagic larvae with high dispersal rates (McLean, Mouillot, Goascoz, Schlaich, \& Auber, 2019; Rijnsdorp, Peck, Engelhard, Möllmann, \& Pinnegar, 2009). These species are further believed to have greater long-term adaptive and evolutionary capacity given their quick population turnover and greater potential for rapid natural selection (Rijnsdorp et al., 2009). Beyond changes in life history traits, we also found that communities converged toward species with higher thermal preferences. Our results therefore suggest that North Sea fish communities are converging toward species' with traits more adapted to warmer conditions (Buisson, Grenouillet, Villéger, Canal, \& Laffaille, 2013; Fukami, Martijn, Mortimer \& Putten, 2005; Molinos et al., 2016). Previous studies have suggested that as natural selection acts on species' traits associated with fitness, environmental filters should push communities toward similar traits if those traits are well-adapted for environmental conditions, irrespective of the species carrying them (Fukami, Martijn, Mortimer \& Putten, 2005; Weiher \& Keddy, 1995; Winemiller, Fitzgerald, Bower, \& Pianka, 2015). Additionally, modelling-based studies have suggested that trait convergence and trait homogenization are likely under climate change, as trait diversity may diminish through declines in specialists and increases in generalists (Buisson et al., 2013). Our results therefore support prior literature hypothesizing trait convergence in communities exposed to climate warming.

This article is protected by copyright. All rights reserved. 
Taxonomically, we found that the northern North Sea became progressively more 'north-like' while the south became progressively more 'south-like', leading to overall divergence in community structure. This result suggests that taxonomic changes were driven not only by increases in existing populations, but also by influxes of fishes through the North Atlantic (around Scotland) and English Channel. While both the north and south became increasingly characterized by small, fast-growing pelagics with higher thermal preferences, this was driven more so by horse mackerel and argentine in the north and by sprat and anchovy in the south. Previous studies have demonstrated major increases in horse mackerel in the northern North Sea in association with climate cycles and increases in chlorophyll $a$ (Reid, de Fatima Borges, \& Svendsen, 2001). Beare et al. (2004) additionally documented a long-term influx of species with warm southerly affinities coming from over the top of Scotland. In the southern North Sea, McLean et al. (2018) documented a northward shift of small pelagic fishes from the eastern English Channel, while Hiddink \& Ter Hofstede (2008) observed increasing species richness as warm southerly communities shifted northward over time. Edwards, John, Hunt, \& Lindley (1999) also documented an inflow of oceanic waters and plankton into both the southern and northern North Sea in the late 1990s that likely facilitated the influx of small pelagic fishes. Thus, as the ecosystem has changed and environmental conditions have become more favorable for small, rapidly-growing fishes with higher thermal preferences, different 'winner' species have likely shifted into the North Sea through both the northerly and southerly openings, leading to taxonomic divergence through time.

This study could not fully examine the potential impact of fishing pressure on spatiotemporal patterns in taxonomic and trait structure, owing to a lack of long-term, spatiallyresolved fishing data. However, we were able to examine the spatial relationship between fish community structure and fishing effort, using temporally-averaged data from available 
timeframes. We found that distinct spatial differences in fish community structure between the southern and northern North Sea were also reflected in fishing effort, which was more concentrated in the shallow, productive southern North Sea (Jennings et al., 1999). Pecuchet et al. (2018) previously showed that fishing effort was related to the distribution of fish traits in the North Sea; however, the authors concluded that fishing effort likely followed spatial patterns in fish communities, because targeted and non-targeted species differ in trait composition. Our results support this hypothesis, as higher fishing effort in the southern North Sea likely reflected both higher accessibility, because the southern North Sea has a greater coastline and is substantially shallower than the north, as well as higher year-round primary productivity. Yet, it should be acknowledged that the data used here were limited to a five-year time period and may not represent spatial trends in fishing pressure for the overall time series, particularly as overall fishing effort has decreased in recent decades (ICES, 2018). Beukhof, Dencker, Pecuchet, \& Lindegren (2019) also examined spatial and temporal patterns in life history traits and concluded that temporal changes in certain traits, notably body size, were likely influenced by fishing pressure. Thus, although it appears that fishing effort followed accessibility and differences in biological production, historical fishing pressure on large demersal fishes likely reinforced the increase in small, rapidly-growing fishes in recent decades. Additionally, although mean thermal preferences have increased throughout the North Sea as the ecosystem has warmed, the increase in small, opportunistic species suggests that heavy exploitation has selected for more fishing-resilient species over time. Assessing the long-term impacts of fishing pressure in different areas of the North Sea would be a valuable extension of this study, and future studies on trait structure should aim to disentangle the relative contributions of warming vs. fishing, particularly for informing models. 
Previous studies examining taxonomic and trait changes in terrestrial communities have found that biotic homogenization often results from intense land-use (e.g., farming, road building), because wide-spread generalists can replace specialists following disturbance (Newbold et al., 2018). In marine systems, intense bottom-trawling and coastal development can degrade or eliminate important habitats that some species depend on, particularly demersal species (De Groot, 1984; Sguotti, Lynam, García-Carreras, Ellis, \& Engelhard, 2016). In the southern North Sea, important habitats like oyster beds have been progressively replaced by sand and gravel over time due to chronic human impacts (Callaway et al., 2002; Houziaux, Fettweis, Francken, \& Van Lancker, 2011). Thus, habitat loss and degradation throughout the North Sea could have also contributed to trait homogenization by reducing the relative abundance of specialist species and long-lived demersal species and by favoring pelagic species with fewer habitat requirements.

Our findings provide insight for sustainable development that could be integrated into predictive models estimating changes in community structure under climate change, as well as fisheries and ecosystem-based management strategies. For example, combining data on trait-environment relationships with habitat models may reveal how communities will unfold in the future, with potential implications for ecosystem functioning (Buisson et al., 2013). Future studies should therefore attempt to identify consistent trait-environment relationships in combination with habitat modelling to predict future changes in trait structure across regions with different species pools. With the emergence of trait-based approaches, fisheries and ecosystem-based management should also move toward maintaining and managing the trait structure of communities rather than on a species-by-species basis (Cadotte et al., 2011; Dee et al., 2016; D'agata et al., 2016). Management strategies that incorporate predicted changes in trait structure will be better able to anticipate how communities will respond to exploitation regardless of species composition.

This article is protected by copyright. All rights reserved. 
Here, a trait-based approach uncovered important insights into community assembly and environmental filtering that was not possible with a purely species-based approach, and the ability to transcend species and apply findings across systems is an important strength of trait-based ecology (Mcgill, Enquist, Weiher, \& Westoby, 2006; Winemiller et al., 2015); However, while we documented spatial shifts in trait structure over time, we are unable to explain the potential consequences for the overall ecosystem, as studies linking fish traits to ecosystem processes and functions are currently lacking (Villéger et al., 2017). We were also unable to account for ontogenetic shifts in trait values or intraspecific trait variation, as we used single, fixed trait values for each species. For instance, fishing pressure is known to decrease size and age at maturity within species, and species may exhibit regional differences in life history traits. Using single trait values per species does not permit incorporating such demographic information. Additionally, we integrated multiple traits to examine the overall spatio-temporal dynamics of fish community structure and did not evaluate the dynamics of individual traits, however such approaches are useful for identifying key traits exhibiting the greatest individual changes (Beukhof, Dencker, Pecuchet, \& Lindegren, 2019; Engelhard et al., 2011; Henriques et al., 2017). Future studies should also examine temporal changes in spatial trait structure over larger geographic scales using multi- and single-trait approaches to identify macro-ecological shifts in trait structure and whether certain traits are shifting or retreating poleward (Frainer et al., 2017). As with all trait-based studies, trait choices ultimately determine research conclusions, and if we had used a different set of ecological traits we may have reached different conclusions. Thus, while the findings of this study appear broadly applicable, our results are limited to the set of traits (and species) used and to the spatial and temporal scales examined. Finally, while this study examined and compared spatio-temporal trends in taxonomic and trait-based community structure, we were unable to 
fully assess the relative importance of different environmental drivers (e.g., climate vs. fishing) due to a lack of spatially-resolved, long-term data.

While more studies are using trait-based approaches, few have compared long-term spatio-temporal patterns between taxonomic and trait structure. Our results show that fish communities are likely to shift toward trait structures associated with emerging environmental conditions, and that this can be achieved through entirely different species pools. As global environmental change continues, trait convergence and homogenization are likely to occur in similar environments worldwide, particularly as communities shift toward trait structures more adapted to warming conditions.

\section{Acknowledgements}

This study was supported by Electricité de France (RESTICLIM and ECLIPSE project), IFREMER (ECLIPSE project), Région Hauts-de-France and the Foundation for Research on Biodiversity (ECLIPSE project, contract no. astre 2014-10824). ML was supported by the VKR Center for Ocean Life and a VILLUM fonden research grant (13159).

This article is protected by copyright. All rights reserved. 


\section{References}

Aadland, L. (1993). Stream Habitat Types: Their Fish Assemblages and Relationship to Flow. North American Journal of Fisheries Management, 13(4), 790-806. https://doi.org/10.1577/1548-8675(1993)013<0790:SHTTFA>2.3.CO;2

Adams, P. B. (1980). Life history patterns in marine fishes and their consequences for fisheries management. Fishery Bulletin, 78(1), 1-12.

Aldridge, J. N., \& Davies, A. M. (1993). A high-resolution three-dimensional hydrodynamic tidal model of the eastern Irish sea. Journal of Physical Oceanography, 23(2), 207224. https://doi.org/10.1175/1520-0485(1993)023<0207:AHRTDH>2.0.CO;2

Allgeier, J. E., Burkepile, D. E., \& Layman, C. A. (2017). Animal pee in the sea: consumermediated nutrient dynamics in the world's changing oceans. Global Change Biology, 23(6), 2166-2178. https://doi.org/10.1111/gcb.13625

Auber, A., Travers-Trolet, M., Villanueva, M. C., \& Ernande, B. (2015). Regime Shift in an Exploited Fish Community Related to Natural Climate Oscillations. PLoS ONE, 10(7). https://doi.org/10.1371/journal.pone.0129883

Baiser, B., \& Lockwood, J. L. (2011). The relationship between functional and taxonomic homogenization. Global Ecology and Biogeography, 20(1), 134-144. https://doi.org/10.1111/j.1466-8238.2010.00583.x

Bascompte, J., Melián, C. J., \& Sala, E. (2005). Interaction strength combinations and the overfishing of a marine food web. Proceedings of the National Academy of Sciences, 105(15), 5443-5447.

Baselga, A. (2017). Partitioning abundance-based multiple-site dissimilarity into components: balanced variation in abundance and abundance gradients. Methods in Ecology and Evolution, 8(7), 799-808. https://doi.org/10.1111/2041-210X.12693

This article is protected by copyright. All rights reserved. 
Beukhof, E., Dencker, T.S., Pecuchet, L., \& Lindegren, M. (2019). Spatio-temporal variation in marine fish traits reveals community-wide responses to environmental change. Marine Ecology Progress Series, 610, 205-222.

Borcard, D., Gillet, F., \& Legendre, P. (2011). Numerical ecology with R. Springer Science \& Business Media.

Botta-Dukát, Z. (2005). Rao's quadratic entropy as a measure of functional diversity based on multiple traits. Journal of Vegetation Science, 16(5), 533-540.

Bremner, J., Rogers, S. I., \& Frid, C. L. J. (2003). Assessing functional diversity in marine benthic ecosystems: a comparison of approaches. Marine Ecology Progress Series, $254,11-25$.

Brown, J. H., Gillooly, J. F., Allen, A. P., Savage, V. M., \& West, G. B. (2004). Toward a metabolic theory of ecology. Ecology, 85(7), 1771-1789.

Buisson, L., Grenouillet, G., Villéger, S., Canal, J., \& Laffaille, P. (2013). Toward a loss of functional diversity in stream fish assemblages under climate change. Global Change Biology, 19(2), 387-400.

Cadotte, M. W., Carscadden, K., \& Mirotchnick, N. (2011). Beyond species: functional diversity and the maintenance of ecological processes and services. Journal of Applied Ecology, 48(5), 1079-1087.

Callaway, R., Alsvåg, J., De Boois, I., Cotter, J., Ford, A., Hinz, H., ... Piet, G. (2002). Diversity and community structure of epibenthic invertebrates and fish in the North Sea. ICES Journal of Marine Science, 59(6), 1199-1214.

Chao, A., Chiu, C.-H., Villéger, S., Sun, I.-F., Thorn, S., Lin, Y.-C., ... Sherwin, W. B. (2019). An attribute-diversity approach to functional diversity, functional beta diversity, and related (dis)similarity measures. Ecological Monographs, 89(2), e01343. https://doi.org/10.1002/ecm.1343

This article is protected by copyright. All rights reserved. 
Cheung, W. W., Watson, R., \& Pauly, D. (2013). Signature of ocean warming in global fisheries catch. Nature, 497(7449), 365-368.

Clare, D. S., Robinson, L. A., \& Frid, C. L. J. (2015). Community variability and ecological functioning: 40 years of change in the North Sea benthos. Marine Environmental Research, 107, 24-34. https://doi.org/10.1016/j.marenvres.2015.03.012

Clavel, J., Julliard, R., \& Devictor, V. (2011). Worldwide decline of specialist species: toward a global functional homogenization? Frontiers in Ecology and the Environment, 9(4), 222-228. https://doi.org/10.1890/080216

Beare, D. J., Burns, F., Greig, A., Jones, E. G., Peach, K., Kienzle, M., ... Reid, D. G. (2004). Long-term increases in prevalence of North Sea fishes having southern biogeographic affinities. Marine Ecology Progress Series, 284, 269-278.

D’agata, S., Mouillot, D., Wantiez, L., Friedlander, A. M., Kulbicki, M., \& Vigliola, L. (2016). Marine reserves lag behind wilderness in the conservation of key functional roles. Nature Communications, 7, 12000. https://doi.org/10.1038/ncomms12000

De Groot, S. (1984). The impact of bottom trawling on benthic fauna of the North Sea. Ocean Management, 9(3-4), 177-190.

Dee, L. E., Miller, S. J., Peavey, L. E., Bradley, D., Gentry, R. R., Startz, R., ... Lester, S. E. (2016). Functional diversity of catch mitigates negative effects of temperature variability on fisheries yields. Proceedings of the Royal Society B: Biological Sciences, 283(1836). https://doi.org/10.1098/rspb.2016.1435

Dencker, T. S., Pecuchet, L., Beukhof, E., Richardson, K., Payne, M. R., \& Lindegren, M. (2017). Temporal and spatial differences between taxonomic and trait biodiversity in a large marine ecosystem: Causes and consequences. PloS One, 12(12), e0189731.

Devictor, V., Julliard, R., Clavel, J., Jiguet, F., Lee, A., \& Couvet, D. (2008). Functional biotic homogenization of bird communities in disturbed landscapes. Global Ecology

This article is protected by copyright. All rights reserved. 
and Biogeography, 17(2), 252-261. https://doi.org/10.1111/j.14668238.2007.00364.x

Díaz, S., \& Cabido, M. (2001). Vive la difference: plant functional diversity matters to ecosystem processes. Trends in Ecology \& Evolution, 16(11), 646-655.

Dormann, C. F., Elith, J., Bacher, S., Buchmann, C., Carl, G., Carré, G., ... Lautenbach, S. (2013). Collinearity: a review of methods to deal with it and a simulation study evaluating their performance. Ecography, 36(1), 27-46. https://doi.org/10.1111/j.1600-0587.2012.07348.x

Duffy, J. E., Cardinale, B. J., France, K. E., McIntyre, P. B., Thébault, E., \& Loreau, M. (2007). The functional role of biodiversity in ecosystems: incorporating trophic complexity. Ecology Letters, 10(6), 522-538. https://doi.org/10.1111/j.14610248.2007.01037.x

Edwards, M., John, A. W. G., Hunt, H. G., \& Lindley, J. A. (1999). Exceptional influx of oceanic species into the North Sea late 1997. Journal of the Marine Biological Association of the United Kingdom, 79(4), 737-739.

Engelhard, G. H., Ellis, J. R., Payne, M. R., ter Hofstede, R., \& Pinnegar, J. K. (2011). Ecotypes as a concept for exploring responses to climate change in fish assemblages. ICES Journal of Marine Science, 68(3), 580-591. https://doi.org/10.1093/icesjms/fsq183

Flanagan, P. H., Jensen, O. P., Morley, J. W., \& Pinsky, M. L. (2019). Response of marine communities to local temperature changes. Ecography, 42(1), 214-224. https://doi.org/10.1111/ecog.03961

Fossheim, M., Primicerio, R., Johannesen, E., Ingvaldsen, R. B., Aschan, M. M., \& Dolgov, A. V. (2015). Recent warming leads to a rapid borealization of fish communities in the Arctic. Nature Climate Change, 5, 673.

This article is protected by copyright. All rights reserved. 
Frainer, A., Primicerio, R., Kortsch, S., Aune, M., Dolgov, A. V., Fossheim, M., \& Aschan, M. M. (2017). Climate-driven changes in functional biogeography of Arctic marine fish communities. Proceedings of the National Academy of Sciences, 114(46), 1220212207.

Frenette-Dussault, C., Shipley, B., Meziane, D., \& Hingrat, Y. (2013). Trait-based climate change predictions of plant community structure in arid steppes. Journal of Ecology, 101(2), 484-492.

Frid, C. L. J., Harwood, K. G., Hall, S. J., \& Hall, J. A. (2000). Long-term changes in the benthic communities on North Sea fishing grounds. ICES Journal of Marine Science, 57(5), 1303-1309. https://doi.org/10.1006/jmsc.2000.0900

Froese, R., \& Pauly, D. (2012). FishBase (www database). Retrieved from http://www.fishbase.org.

Fukami, T., Martijn, B. T., Mortimer, S. R., \& Putten, W. H. (2005). Species divergence and trait convergence in experimental plant community assembly. Ecology Letters, 8(12), 1283-1290. https://doi.org/10.1111/j.1461-0248.2005.00829.x

Gislason, H. (1994). Ecosystem effects of fishing activities in the North Sea. Environmental Perspective for the Northern Seas, 29(6), 520-527. https://doi.org/10.1016/0025$326 X(94) 90680-7$

Givan, O., Edelist, D., Sonin, O., \& Belmaker, J. (2018). Thermal affinity as the dominant factor changing Mediterranean fish abundances. Global Change Biology, 24(1), e80e89.

Gohin, F. (2011). Annual cycles of chlorophyll-a, non-algal suspended particulate matter, and turbidity observed from space and in-situ in coastal waters. Ocean Science, 7(5), 705.

This article is protected by copyright. All rights reserved. 
Gravel, D., Massol, F., \& Leibold, M. A. (2016). Stability and complexity in model metaecosystems. Nature Communications, 7, 12457. https://doi.org/10.1038/ncomms12457

Gross, M. R., \& Sargent, R. C. (2015). The Evolution of Male and Female Parental Care in Fishes. American Zoologist, 25(3), 807-822. https://doi.org/10.1093/icb/25.3.807

Henriques, S., Guilhaumon, F., Villéger, S., Amoroso, S., França, S., Pasquaud, S., ... Vasconcelos, R. P. (2017). Biogeographical region and environmental conditions drive functional traits of estuarine fish assemblages worldwide. Fish and Fisheries, 18(4), 752-771.

Hiddink, J., \& Ter Hofstede, R. (2008). Climate induced increases in species richness of marine fishes. Global Change Biology, 14(3), 453-460.

Hobday, A. J., \& Pecl, G. T. (2014). Identification of global marine hotspots: sentinels for change and vanguards for adaptation action. Reviews in Fish Biology and Fisheries, $24(2), 415-425$.

Holmlund, C. M., \& Hammer, M. (1999). Ecosystem services generated by fish populations. Ecological Economics, 29.

Houziaux, J.-S., Fettweis, M., Francken, F., \& Van Lancker, V. (2011). Historic (1900) seafloor composition in the Belgian-Dutch part of the North Sea: a reconstruction based on calibrated visual sediment descriptions. Continental Shelf Research, 31(10), 1043-1056.

Huxel, G. R., \& McCann, K. (1998). Food web stability: the influence of trophic flows across habitats. The American Naturalist, 152(3), 460-469.

ICES. (2018). Greater North Sea Ecoregion - Fisheries Overview. Retrieved from https://doi.org/10.17895/ices.pub.4647

This article is protected by copyright. All rights reserved. 
Jennings, S., Alvsvåg, J., Cotter, A. J. ., Ehrich, S., Greenstreet, S. P. ., Jarre-Teichmann, A., ... Smedstad, O. (1999). Fishing effects in northeast Atlantic shelf seas: patterns in fishing effort, diversity and community structure. III. International trawling effort in the North Sea: an analysis of spatial and temporal trends. Fisheries Research, 40(2), 125-134. https://doi.org/10.1016/S0165-7836(98)00208-2

Keck, B. P., Marion, Z. H., Martin, D. J., Kaufman, J. C., Harden, C. P., Schwartz, J. S., \& Strange, R. J. (2014). Fish Functional Traits Correlated with Environmental Variables in a Temperate Biodiversity Hotspot. PLOS ONE, 9(3), e93237. https://doi.org/10.1371/journal.pone.0093237

Kenny, A. J., Skjoldal, H. R., Engelhard, G. H., Kershaw, P. J., \& Reid, J. B. (2009). An integrated approach for assessing the relative significance of human pressures and environmental forcing on the status of Large Marine Ecosystems. Progress in Oceanography, 81(1), 132-148. https://doi.org/10.1016/j.pocean.2009.04.007

Lambert, Y. (2008). Why should we closely monitor fecundity in marine fish populations. $J$. Northw. Atl. Fish. Sci, 41, 93-106.

Laughlin, D. C. (2014). The intrinsic dimensionality of plant traits and its relevance to community assembly. Journal of Ecology, 102(1), 186-193.

Lavorel, S., \& Garnier, E. (2002). Predicting changes in community composition and ecosystem functioning from plant traits: revisiting the Holy Grail. Functional Ecology, 16(5), 545-556.

Lefcheck, J. S., Bastazini, V. A., \& Griffin, J. N. (2015). Choosing and using multiple traits in functional diversity research. Environmental Conservation, 42(2), 104-107.

Lepš, J., De Bello, F., Lavorel, S., \& Berman, S. (2006). Quantifying and interpreting functional diversity of natural communities: practical considerations matter. Preslia, 78(4), 481-501.

This article is protected by copyright. All rights reserved. 
Magurran, A. E., Dornelas, M., Moyes, F., Gotelli, N. J., \& McGill, B. (2015). Rapid biotic homogenization of marine fish assemblages. Nature Communications, 6, 8405 .

Mcgill, B., Enquist, B., Weiher, E., \& Westoby, M. (2006). Rebuilding community ecology from functional traits. Trends in Ecology \& Evolution, 21(4), 178-185. https://doi.org/10.1016/j.tree.2006.02.002

McLean, M. J., Mouillot, D., Goascoz, N., Schlaich, I., \& Auber, A. (2019). Functional reorganization of marine fish nurseries under climate warming. Global Change Biology, 25(2), 660-674. https://doi.org/10.1111/gcb.14501

McLean M., Mouillot D., \& Auber A. (2018). Ecological and life history traits explain a climate-induced shift in a temperate marine fish community. Marine Ecology Progress Series, 606, 175-186.

McLean, M., Mouillot, D., Lindegren, M., Engelhard, G., Villéger, S., Marchal, P., ... Auber, A. (2018). A climate-driven functional inversion of connected marine ecosystems. Current Biology, 28(22), 3654-3660.e3. https://doi.org/10.1016/j.cub.2018.09.050

Molinos, J. G., Halpern, B. S., Schoeman, D. S., Brown, C. J., Kiessling, W., Moore, P. J., ... Burrows, M. T. (2016). Climate velocity and the future global redistribution of marine biodiversity. Nature Climate Change, 6(1), 83.

Monnet, A. C., Jiguet, F., Meynard, C. N., Mouillot, D., Mouquet, N., Thuiller, W., \& Devictor, V. (2014). Asynchrony of taxonomic, functional and phylogenetic diversity in birds: Asynchrony of bird diversities. Global Ecology and Biogeography, 23(7), 780-788. https://doi.org/10.1111/geb.12179

Montero-Serra, I., Edwards, M., \& Genner, M.J. (2014). Warming shelf seas drive the subtropicalization of European pelagic fish communities. Global Change Biology, 21(1), 144-153. https://doi.org/10.1111/gcb.12747

This article is protected by copyright. All rights reserved. 
Mouillot, D., Villeger, S., Parravicini, V., Kulbicki, M., Arias-Gonzalez, J. E., Bender, M., ... Bellwood, D. R. (2014). Functional over-redundancy and high functional vulnerability in global fish faunas on tropical reefs. Proceedings of the National Academy of Sciences, 111(38), 13757-13762. https://doi.org/10.1073/pnas.1317625111

Mouillot, D., Bellwood, D. R., Baraloto, C., Chave, J., Galzin, R., Harmelin-Vivien, M., ... Mouquet, N. (2013). Rare species support vulnerable functions in high-diversity ecosystems. PLoS Biology, 11(5), e1001569.

Mouillot, D., Graham, N. A. J., Villéger, S., Mason, N. W. H., \& Bellwood, D. R. (2013). A functional approach reveals community responses to disturbances. Trends in Ecology \& Evolution, 28(3), 167-177. https://doi.org/10.1016/j.tree.2012.10.004

Newbold, T., Hudson, L. N., Contu, S., Hill, S. L. L., Beck, J., Liu, Y., ... Purvis, A. (2018). Widespread winners and narrow-ranged losers: Land use homogenizes biodiversity in local assemblages worldwide. PLOS Biology, 16(12), e2006841. https://doi.org/10.1371/journal.pbio.2006841

Olden, J. D., LeRoy Poff, N., Douglas, M. R., Douglas, M. E., \& Fausch, K. D. (2004). Ecological and evolutionary consequences of biotic homogenization. Trends in Ecology \& Evolution, 19(1), 18-24. https://doi.org/10.1016/j.tree.2003.09.010

Pecuchet, L., Lindegren, M., Hidalgo, M., Delgado, M., Esteban, A., Fock, H. O., ... Payne, M. R. (2017). From traits to life-history strategies: Deconstructing fish community composition across European seas. Global Ecology and Biogeography, 26(7), 812822. https://doi.org/10.1111/geb.12587

Pecuchet, L., Reygondeau, G., Cheung, W. W. L., Licandro, P., van Denderen, P. D., Payne, M. R., \& Lindegren, M. (2018). Spatial distribution of life-history traits and their 
response to environmental gradients across multiple marine taxa. Ecosphere, 9(10), e02460. https://doi.org/10.1002/ecs2.2460

Pecuchet, L., Törnroos, A., \& Lindegren, M. (2016). Patterns and drivers of fish community assembly in a large marine ecosystem. Marine Ecology Progress Series, 546, 239248.

Petchey, O. L., Beckerman, A. P., Riede, J. O., \& Warren, P. H. (2008). Size, foraging, and food web structure. Proceedings of the National Academy of Sciences, 105(11), 41914196.

Petchey, O. L., \& Gaston, K. J. (2006). Functional diversity: back to basics and looking forward. Ecology Letters, 9(6), 741-758. https://doi.org/10.1111/j.14610248.2006.00924.x

Rayner, N., Parker, D. E., Horton, E., Folland, C., Alexander, L., Rowell, D., ... Kaplan, A. (2003). Global analyses of sea surface temperature, sea ice, and night marine air temperature since the late nineteenth century. Journal of Geophysical Research: Atmospheres, 108(D14).

Reid, P. C., de Fatima Borges, M., \& Svendsen, E. (2001). A regime shift in the North Sea circa 1988 linked to changes in the North Sea horse mackerel fishery. Fisheries Research, 50(1), 163-171.

Richardson, L. E., Graham, N. A., Pratchett, M. S., Eurich, J. G., \& Hoey, A. S. (2018). Mass coral bleaching causes biotic homogenization of reef fish assemblages. Global Change Biology, 24(7), 3117-3129.

Rijnsdorp, A. D., Peck, M. A., Engelhard, G. H., Möllmann, C., \& Pinnegar, J. K. (2009). Resolving the effect of climate change on fish populations. ICES Journal of Marine Science, 66(7), 1570-1583. https://doi.org/10.1093/icesjms/fsp056

This article is protected by copyright. All rights reserved. 
Sakschewski, B., von Bloh, W., Boit, A., Poorter, L., Peña-Claros, M., Heinke, J., ... Thonicke, K. (2016). Resilience of Amazon forests emerges from plant trait diversity. Nature Climate Change, 6(11), 1032-1036. https://doi.org/10.1038/nclimate3109

Schneider, F. D., Brose, U., Rall, B. C., \& Guill, C. (2016). Animal diversity and ecosystem functioning in dynamic food webs. Nature Communications, 7, 12718. https://doi.org/10.1038/ncomms12718

Sguotti, C., Lynam, C. P., García-Carreras, B., Ellis, J. R., \& Engelhard, G. H. (2016). Distribution of skates and sharks in the North Sea: 112 years of change. Global Change Biology, 22(8), 2729-2743. https://doi.org/10.1111/gcb.13316

Shipley, B., Laughlin, D. C., Sonnier, G., \& Otfinowski, R. (2011). A strong test of a maximum entropy model of trait-based community assembly. Ecology, 92(2), 507517.

Simpson, S. D., Jennings, S., Johnson, M. P., Blanchard, J. L., Schön, P.-J., Sims, D. W., \& Genner, M. J. (2011). Continental Shelf-Wide Response of a Fish Assemblage to Rapid Warming of the Sea. Current Biology, 21(18), 1565-1570. https://doi.org/10.1016/j.cub.2011.08.016

Skogen, M. D., Svendsen, E., Berntsen, J., Aksnes, D., \& Ulvestad, K. B. (1995). Modelling the primary production in the North Sea using a coupled three-dimensional physicalchemical-biological ocean model. Estuarine, Coastal and Shelf Science, 41(5), 545565.

Somerfield, P. J., Clarke, K. R., Warwick, R. M., \& Dulvy, N. K. (2008). Average functional distinctness as a measure of the composition of assemblages. ICEs Journal of Marine Science: Journal Du Conseil, 65(8), 1462-1468.

Suding, K. N., Lavorel, S., Chapin, F. S., Cornelissen, J. H. C., DíAz, S., Garnier, E., ... Navas, M.-L. (2008). Scaling environmental change through the community-level: a 
trait-based response-and-effect framework for plants. Global Change Biology, 14(5), 1125-1140. https://doi.org/10.1111/j.1365-2486.2008.01557.x

Tillin, H. M., Hiddink, J. G., Jennings, S., \& Kaiser, M. J.. (2006). Chronic bottom trawling alters the functional composition of benthic invertebrate communities on a sea-basin scale. Marine Ecology Progress Series, 318, 31-45.

Villéger, S., Brosse, S., Mouchet, M., Mouillot, D., \& Vanni, M. J. (2017). Functional ecology of fish: current approaches and future challenges. Aquatic Sciences, 1-19.

Villéger, S., Miranda, J. R., Hernández, D. F., \& Mouillot, D. (2010). Contrasting changes in taxonomic vs. functional diversity of tropical fish communities after habitat degradation. Ecological Applications, 20(6), 1512-1522.

Violle, C., Thuiller, W., Mouquet, N., Munoz, F., Kraft, N. J., Cadotte, M. W., ... Mouillot, D. (2017). Functional rarity: the ecology of outliers. Trends in Ecology \& Evolution, $32(5), 356-367$.

Ware, D. (1975). Relation between egg size, growth, and natural mortality of larval fish. Journal of the Fisheries Board of Canada, 32(12), 2503-2512.

Weiher, E., \& Keddy, P. A. (1995). Assembly Rules, Null Models, and Trait Dispersion: New Questions from Old Patterns. Oikos, 74(1), 159. https://doi.org/10.2307/3545686

Wernberg, T., Bennett, S., Babcock, R. C., de Bettignies, T., Cure, K., Depczynski, M., ... Hovey, R. K. (2016). Climate-driven regime shift of a temperate marine ecosystem. Science, 353(6295), 169-172.

White, H. J., Montgomery, W. I., Storchová, L., Hořák, D., \& Lennon, J. J. (2018). Does functional homogenization accompany taxonomic homogenization of British birds and how do biotic factors and climate affect these processes? Ecology and Evolution, 8(15), 7365-7377. https://doi.org/10.1002/ece3.4267

This article is protected by copyright. All rights reserved. 
Winemiller, K. O., \& Rose, K. A. (1992). Patterns of life-history diversification in North American fishes: implications for population regulation. Canadian Journal of Fisheries and Aquatic Sciences, 49(10), 2196-2218.

Winemiller, K. O., Fitzgerald, D. B., Bower, L. M., \& Pianka, E. R. (2015). Functional traits, convergent evolution, and periodic tables of niches. Ecology Letters, 18(8), 737-751. https://doi.org/10.1111/ele.12462

Worm, B., Barbier, E. B., Beaumont, N., Duffy, J. E., Folke, C., Halpern, B. S., ... others. (2006). Impacts of biodiversity loss on ocean ecosystem services. Science, 314(5800), $787-790$.

Zhu, L., Fu, B., Zhu, H., Wang, C., Jiao, L., \& Zhou, J. (2017). Trait choice profoundly affected the ecological conclusions drawn from functional diversity measures. Scientific Reports, 7(1), 3643. 


\section{Figure legends}

FIGURE 1 Maps and ordination biplots showing overall spatio-temporal variation in taxonomic (a-c) and trait structure (d-f) in North Sea fish communities. Maps show northern and southern spatial clusters in taxonomic (a) and trait (d) structure, biplot vectors show the most contributive species (b) and traits (e), and all sites across all time periods are plotted and colored by spatial clusters along with the distribution of points in each cluster on the first axes of the ordinations (c, f).

FIGURE 2 Ordination biplots showing relationships between environmental variables and overall spatio-temporal variation in taxonomic (a-d) and trait structure (e-h) in North Sea fish communities. Adjusted $\mathrm{R}^{2}$ values from redundancy analyses are indicated in the upper-left corner of each plot.

FIGURE 3 Temporal trajectories of southern and northern taxonomic (a) and trait-based (b) clusters in the PCoA and MFA ordination spaces. Cluster positions each year (circles) are shown along the first two axes of ordination spaces and are colored by a temporal gradient from 1983 to 2015 .

FIGURE 4 Temporal krigging-interpolated maps of taxonomic PCoA1 scores (a) and traitbased MFA1 scores (b) showing taxonomic divergence and trait convergence of North Sea fish communities.

FIGURE 5 Temporal changes in spatial dissimilarity in taxonomic and trait structure of North Sea fish communities. Panels a and c show temporal changes in the Euclidean distance between cluster centroids in the ordination spaces (PCoA for taxonomic, MFA for traits). Panels $\mathrm{b}$ and $\mathrm{d}$ show temporal changes in taxonomic (Bray-Curtis) and trait-based (modified Rao's Quadratic Entropy) beta diversity for the entire North Sea. Dotted lines indicate best fits from linear regressions and $\mathrm{R}^{2}$ values are indicated in the upper-left corner of each plot.

This article is protected by copyright. All rights reserved. 
(a)

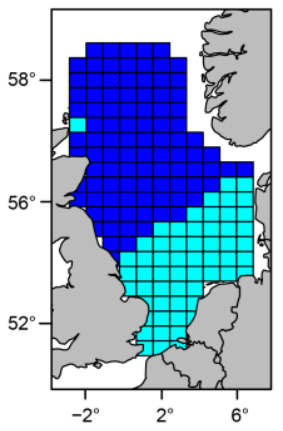

(b)

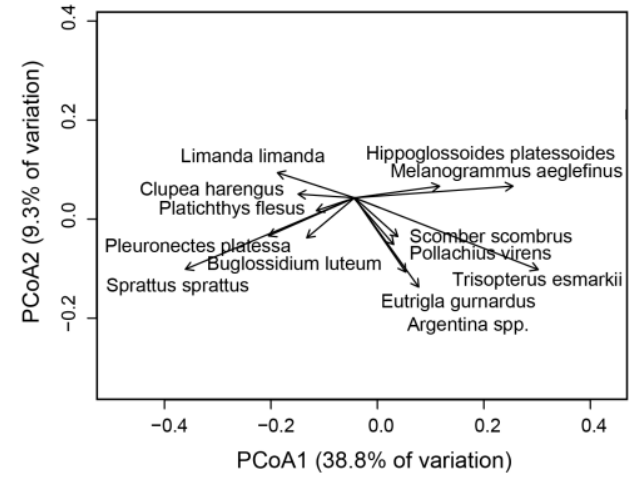

Trait Structure

(d)

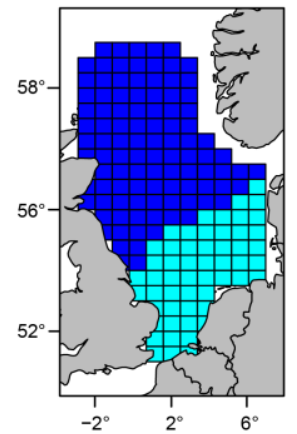

(e)

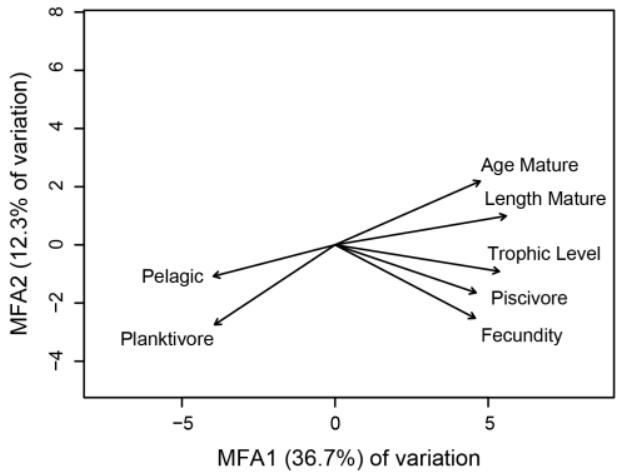

(c)

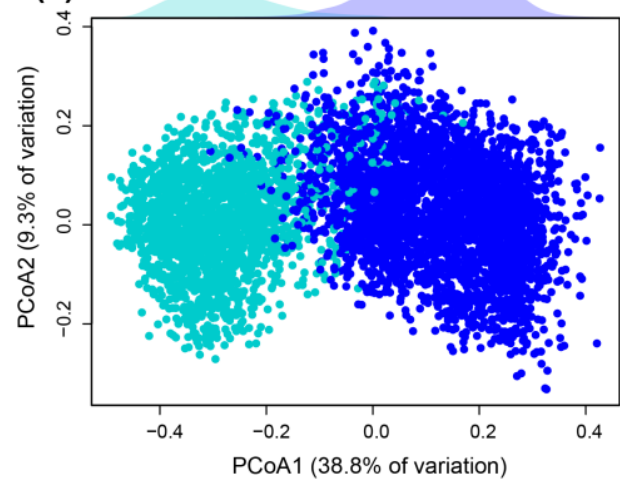

(f)

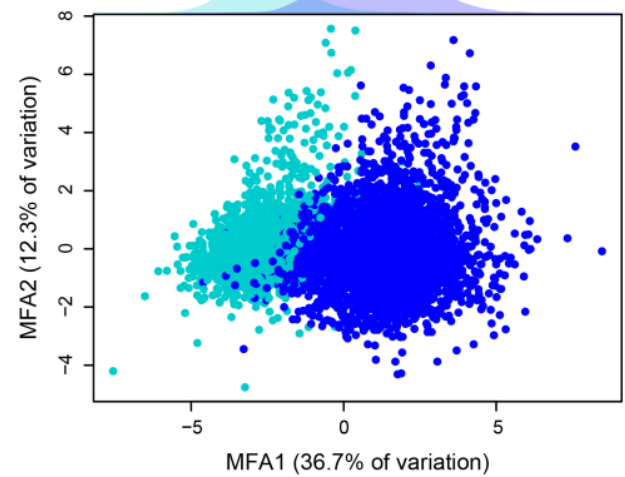

This article is protected by copyright. All rights reserved. 

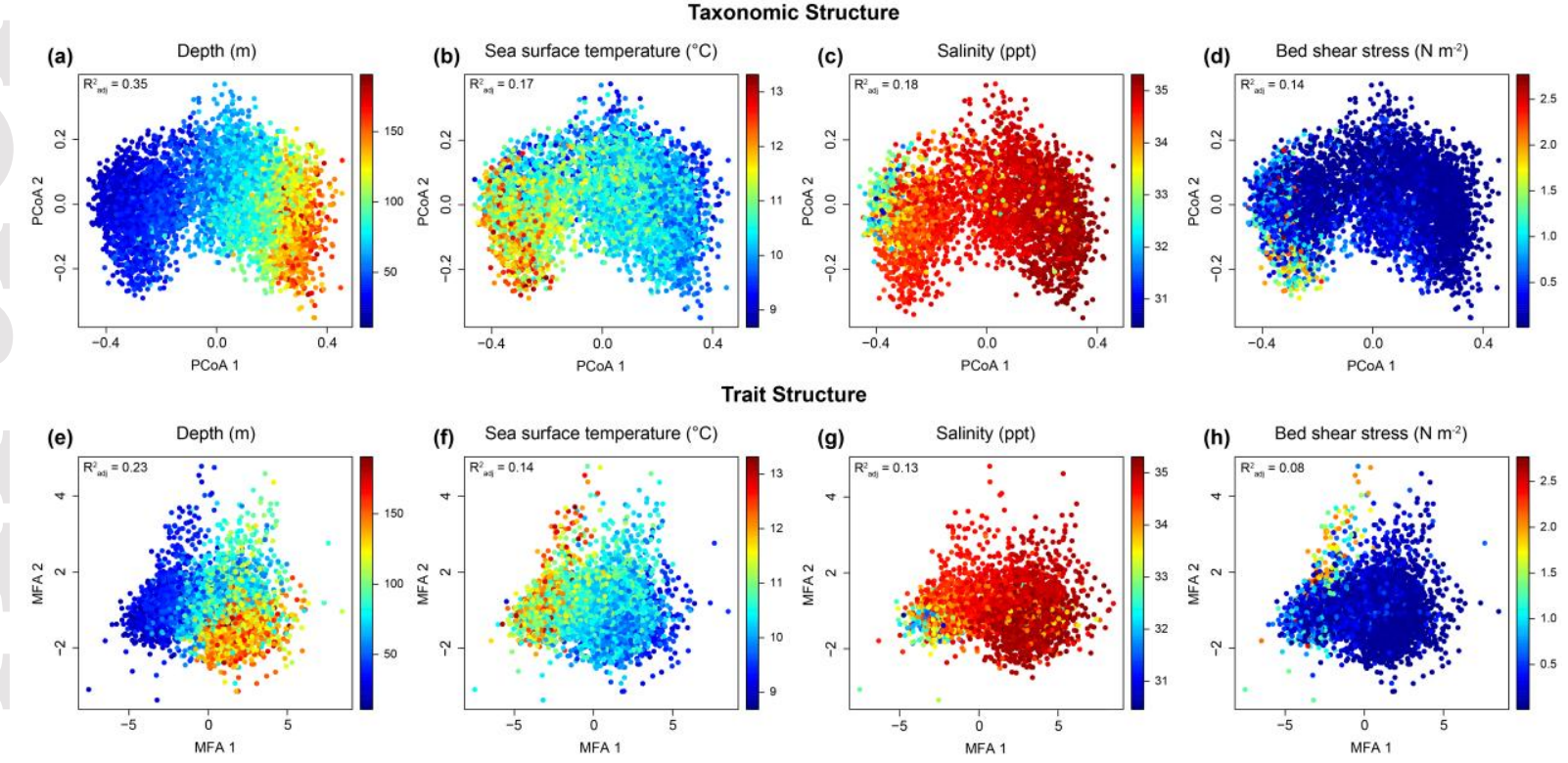

This article is protected by copyright. All rights reserved. 


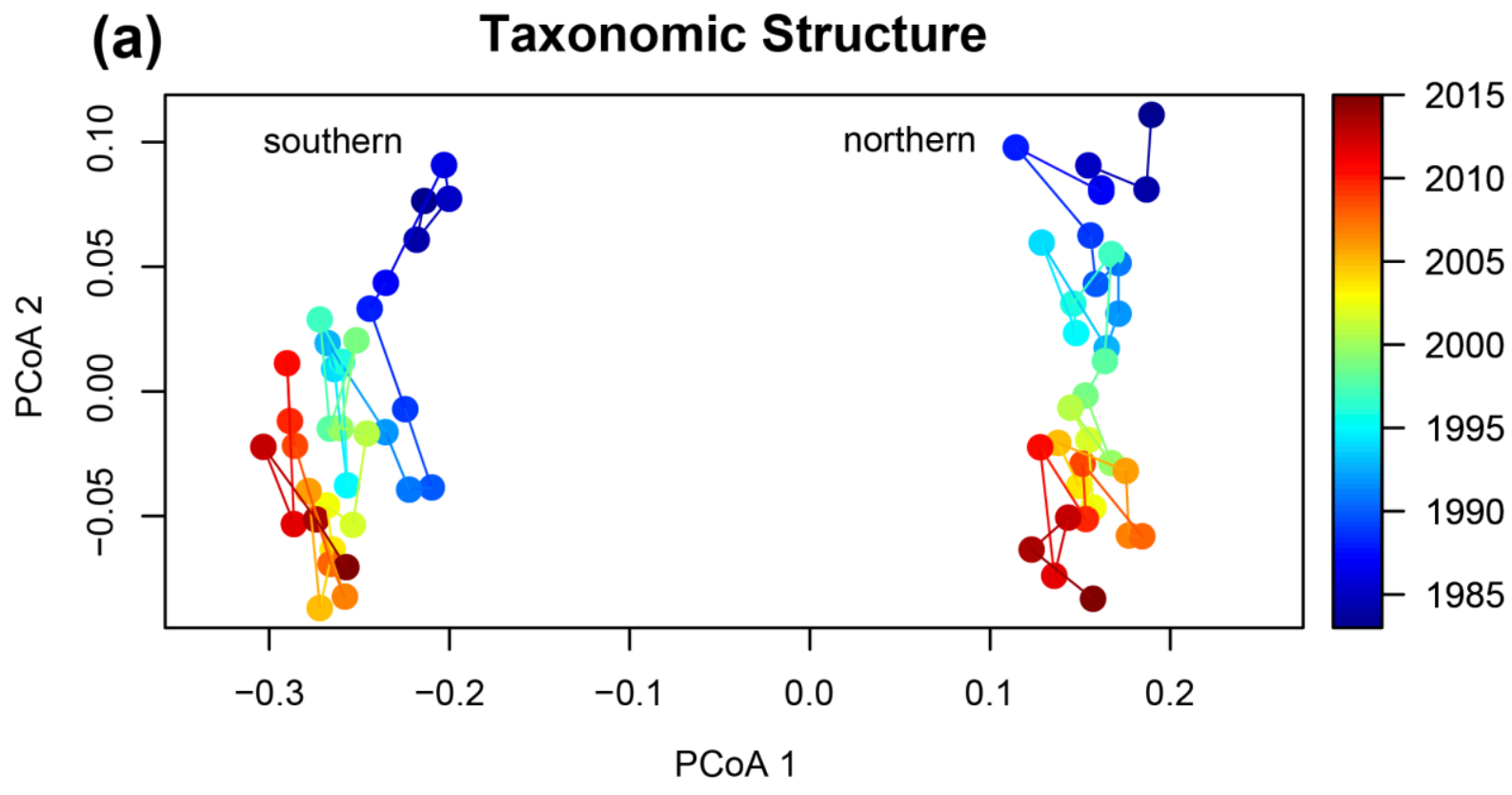

(b) Trait Structure

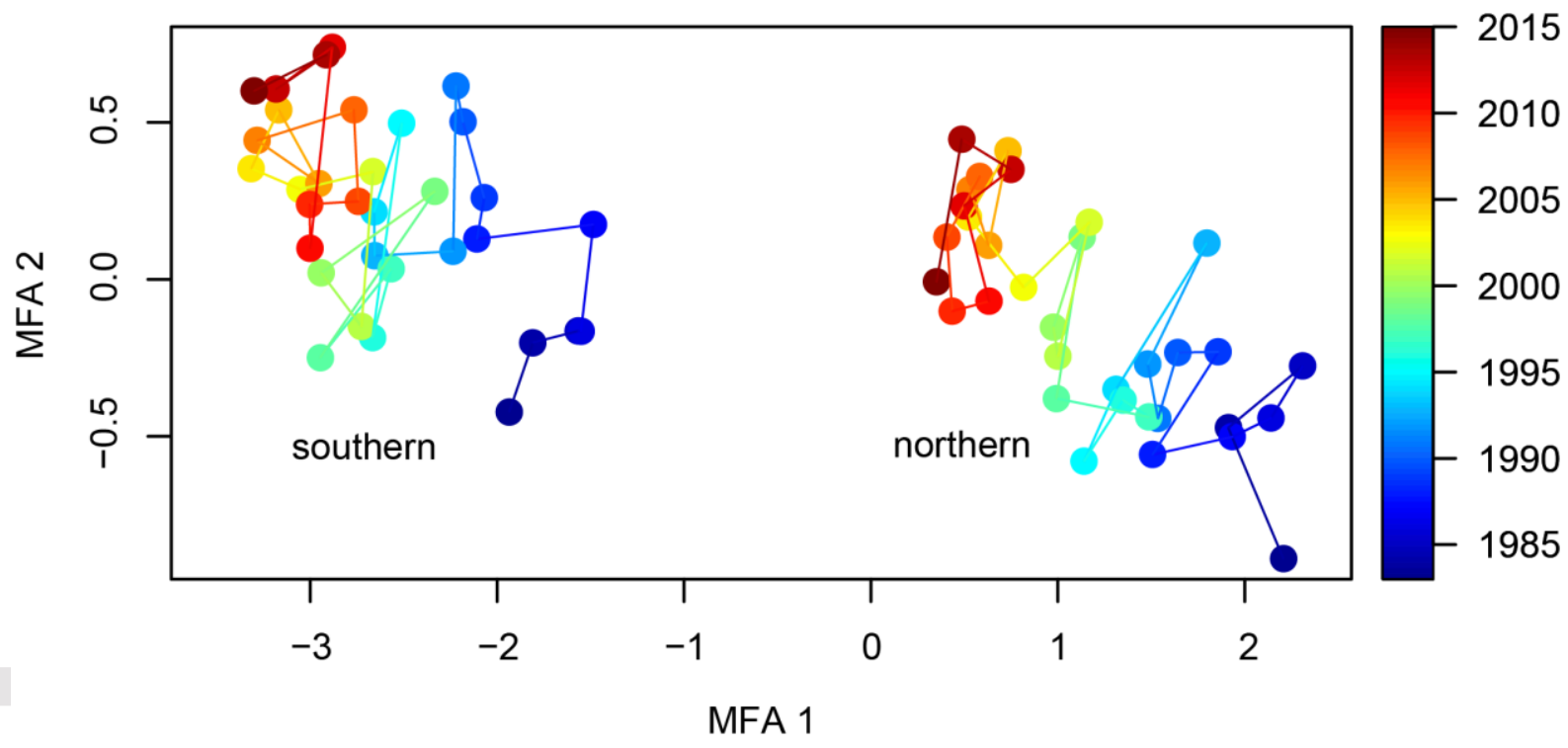



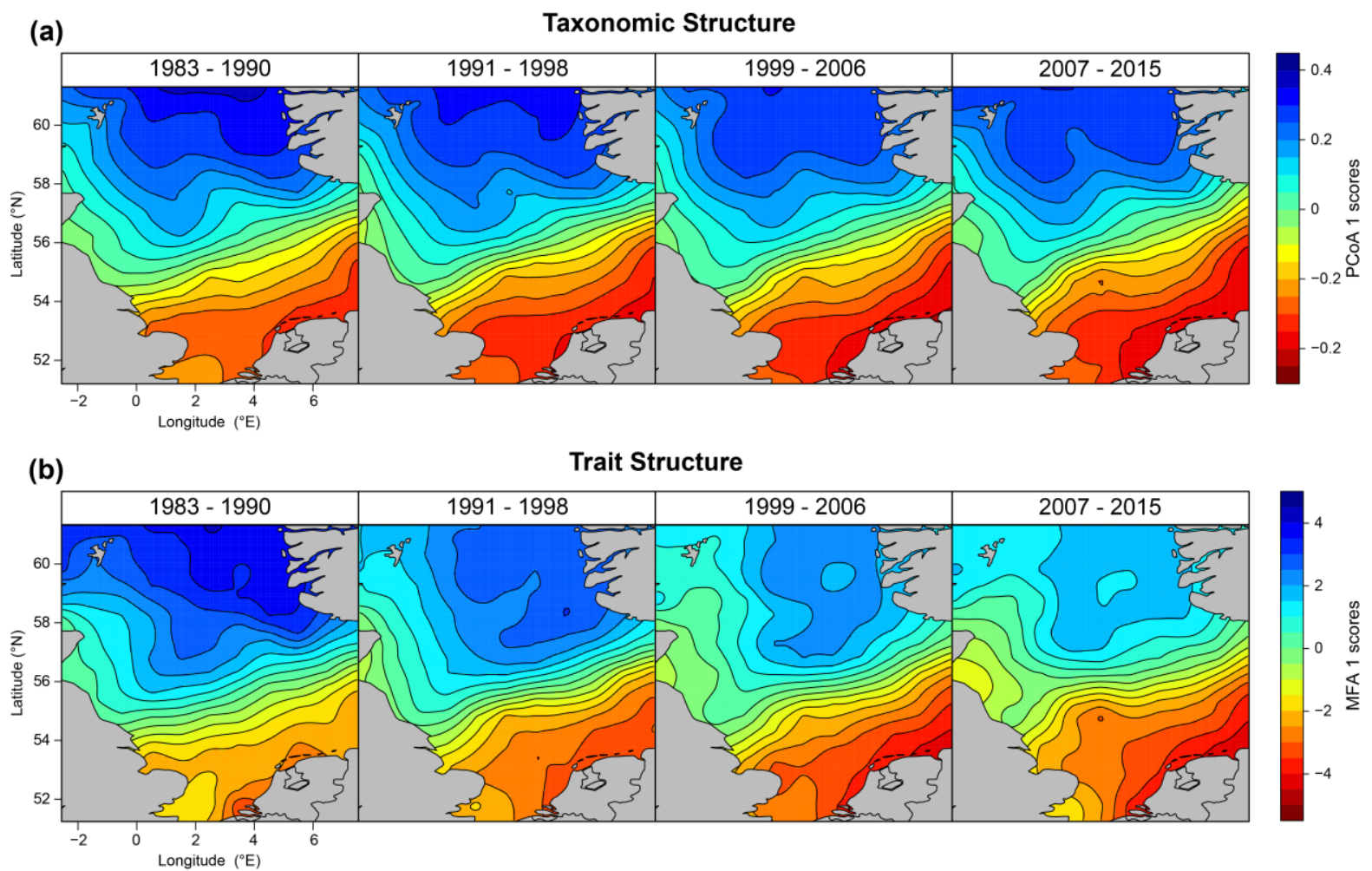

This article is protected by copyright. All rights reserved. 


\section{Taxonomic Structure}
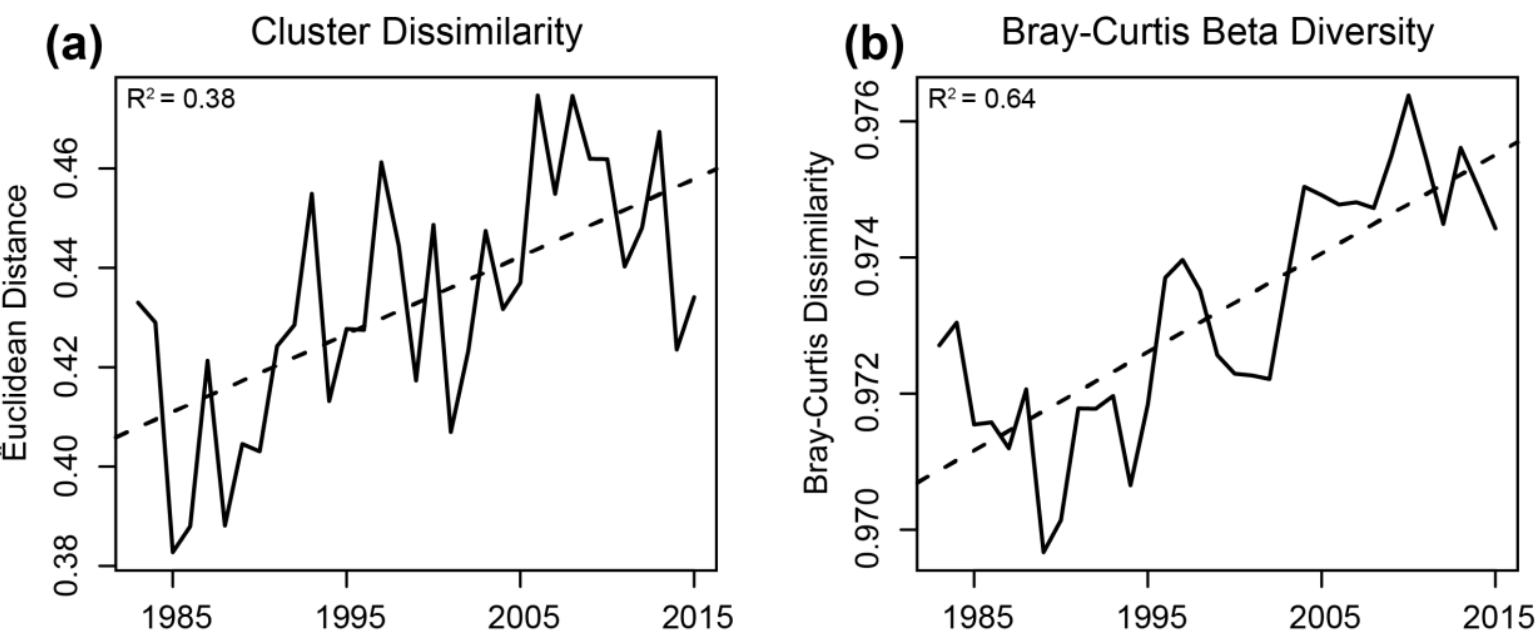

\section{Trait Structure}
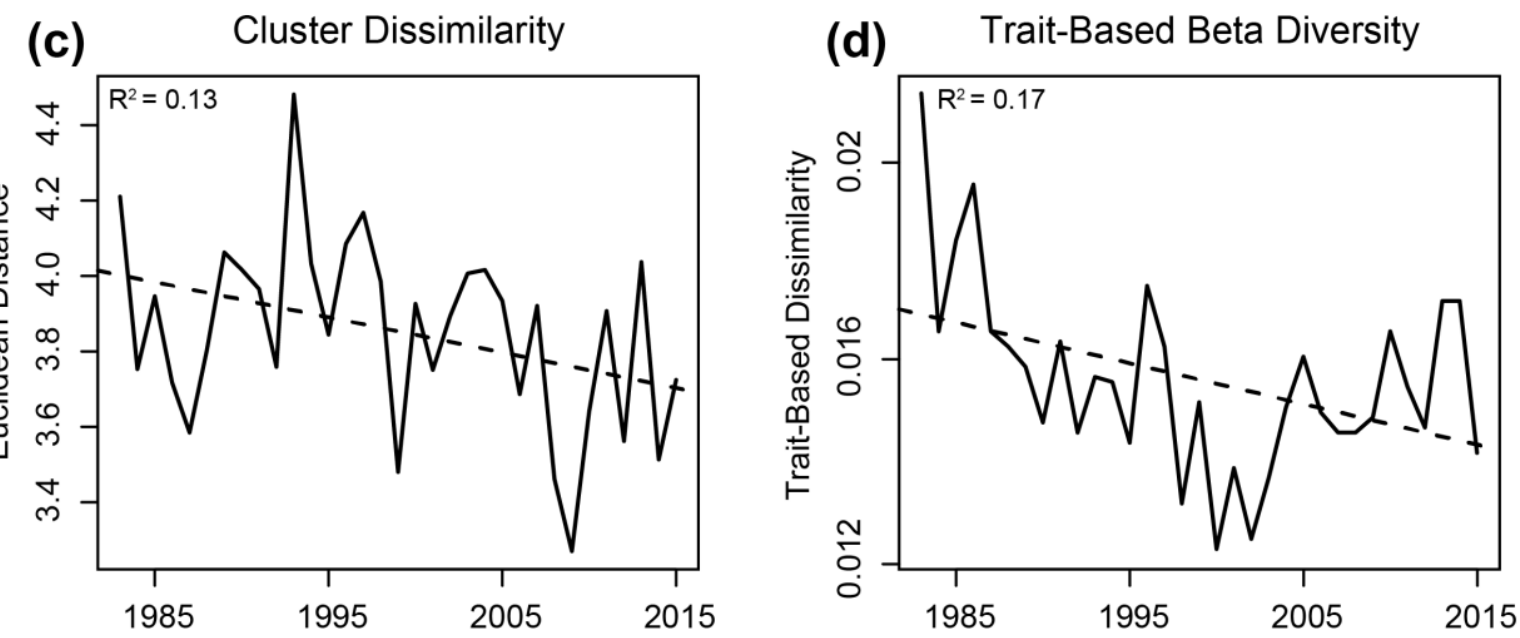